\title{
Outcomes of surgery for young children with multivessel pulmonary vein stenosis
}

\author{
Luis G. Quinonez, MD, ${ }^{\mathrm{a}}$ Kimberlee Gauvreau, $\mathrm{PhD},{ }^{\mathrm{b}}$ Michele Borisuk, NP, ${ }^{\mathrm{a}}$ \\ Christina Ireland, NP, ${ }^{\mathrm{b}}$ Audrey M. Marshall, MD, ${ }^{\mathrm{b}}$ John E. Mayer, MD, ${ }^{\mathrm{a}}$ \\ Kathy J. Jenkins, MD, ${ }^{\mathrm{b}}$ Francis E. Fynn-Thompson, MD, ${ }^{\mathrm{a}}$ and Christopher W. Baird, MD ${ }^{\mathrm{a}}$
}

\begin{abstract}
Objective: We pursued a multimodality approach to the treatment of patients with pulmonary vein stenosis, incorporating sutureless surgical repair, catheter interventions, and adjunctive chemotherapy. We report our outcomes after surgery.

Methods: Between January 2007 and August 2013, 49 patients with multivessel pulmonary vein stenosis underwent operations at our institution. We retrospectively reviewed data from a pulmonary vein stenosis registry and the medical records.

Results: At the time of the index operation, the median patient age was 6 months (range, 32 days-48 months) and weight was $4.9 \mathrm{~kg}$ (range, 2.1-13.4 kg). Fourteen patients $(28 \%)$ died during the follow-up period (median follow-up was 0.5 years [range, 0.04-4.9 years]). There were 2 deaths (4\%) within 30 days. Age at repair $<6$ months, weight at repair $<3 \mathrm{~kg}$, and a preoperative right ventricular systolic pressure $<3 / 4$ systemic were found to be associated with mortality. One patient required repeat operation for recurrent stenosis. Thirty-nine patients $(80 \%)$ underwent postoperative catheterizations. The median number of catheterizations per patient was 2 (range, 0-14). Twenty-nine patients $(59 \%)$ underwent catheterizations with pulmonary vein intervention. The median number of catheterizations with intervention per patient was 1 (range, 0-14). There were no identifiable associations with need for or number of catheterizations with intervention. Ten patients were listed for lung transplantation: 4 patients were de-listed, 3 patients died waiting, and 3 patients underwent transplant.
\end{abstract}

Conclusions: Using a multimodality approach, we observed acceptable early survival after operation in patients with pulmonary vein stenosis, despite the need for catheter reinterventions. Lung transplantation remains a viable option. (J Thorac Cardiovasc Surg 2015;150:911-7)

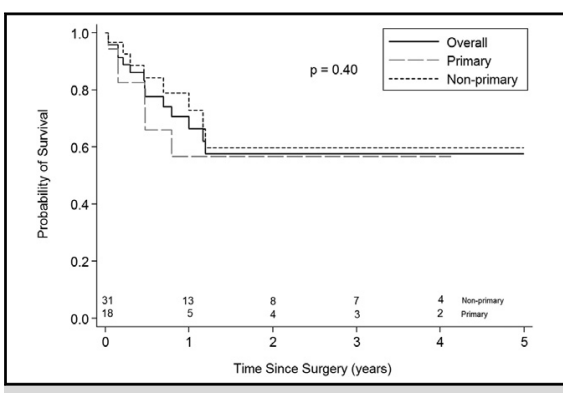

Kaplan-Meier survival curve of patients undergoing operation for multivessel pulmonary vein stenosis.

\section{Central Message}

Children undergoing operation for multivesse PVS have acceptable early survival. Catheterbased reinterventions are common but decrease over time.

Perspective

PVS is a challenging disease and survival is poor We use a multimodality approach, including aggressive surgical resection. With our approach we have achieved acceptable survival. Many patients underwent multiple catheter-based interventions; the frequency decreased with time. Some patients were maintained with ongoing interventions. Surveillance and aggressive treatment of recurrent stenoses is important.

See Editorial page 776 .
Pulmonary vein stenosis (PVS) is a disease of neointimal proliferation of myofibroblasts leading to progressive luminal stenosis and obliteration. ${ }^{1}$ It may occur in isolation or may be associated with congenital heart disease. ${ }^{2-5}$ Catheter-based interventions do not provide effective

\footnotetext{
From the Departments of ${ }^{\mathrm{a} C}$ Cardiac Surgery and ${ }^{\mathrm{b}}$ Cardiology, Boston Children's Hospital, Boston, Mass.

Read at the 94th Annual Meeting of The American Association for Thoracic Surgery, Toronto, Ontario, Canada, April 26-30, 2014.

Received for publication Aug 11, 2014; revisions received May 6, 2015; accepted for publication June 14, 2015; available ahead of print July 26, 2015.

Address for reprints: Luis G. Quinonez, MD, Department of Cardiac Surgery, Boston Children's Hospital, 300 Longwood Ave, Boston, MA 02115 (E-mail: luis. quinonez@cardio.chboston.org).

$0022-5223 / \$ 36.00$

Copyright (C) 2015 by The American Association for Thoracic Surgery

http://dx.doi.org/10.1016/j.jtcvs.2015.06.050
}

long-term relief of stenoses. ${ }^{6,7}$ The survival of patients with PVS has been poor. Surgical interventions to relieve PVS have included unroofing, patching, and sutureless reconstructions. ${ }^{8}$ Surgical series have been limited by small numbers of patients and the results have been generally poor. $^{9-15}$ Lung transplantation has also been reported as a viable treatment. ${ }^{16}$ Adjunctive chemotherapy has been used to improve the outcome of patients with a poor prognosis. ${ }^{17}$ We report our surgical outcomes of infants with multivessel PVS, using a multimodality approach.

\section{METHODS}

Institutional review board approval was obtained for this study. Between January 2007 and August 2013, patients with a diagnosis of multivesse PVS ( $\geq 2$ veins) were identified by review of medical records and a Boston Children's Hospital prospectively collected registry of patients with PVS. 


\section{Abbreviations and Acronyms \\ $\mathrm{CA}=$ circulatory arrest \\ $\mathrm{CPB}=$ cardiopulmonary bypass \\ PVS = pulmonary vein stenosis \\ $\mathrm{RV}=$ right ventricle \\ $\mathrm{RSVP}=$ right ventricular systolic pressure}

Patient characteristics and all available follow-up data were retrospectively collected. The main objective of this study was to document survival after PVS operation at our institution and need for reinterventions for the overall cohort. The secondary objective was to identify risk factors for these outcomes.

\section{Preoperative Imaging}

All patients underwent a transthoracic echocardiogram to assess the status of the pulmonary veins, estimate right ventricle (RV) pressure and function, and identify any other cardiac lesions. All patients had cardiac catheterization to further delineate pulmonary venous anatomy and RV pressure. For this study, the last catheterization before pulmonary vein operation at our institution was used to determine the RV systolic pressure (RVSP) and systemic pressure at rest conditions. If deemed appropriate, PVSs were dilated to decrease pulmonary hypertension. Differential lung perfusion scan, computed tomography, and magnetic resonance imaging were used selectively as adjuvant imaging.

\section{Surgical Technique}

All patients had a median sternotomy and hypothermic $\left(18^{\circ} \mathrm{C}\right)$ cardiopulmonary bypass $(\mathrm{CPB})$ with cardioplegic arrest. The right atrium was generously opened and the septum primum was resected for optimal intracardiac visualization and assessment of the pulmonary vein orifices. Generally, the approach to the right veins was through Sondengaard's groove. The left veins were approached by retracting the myocardial mass superiorly and toward the midline. Using intermittent periods of circulatory arrest (CA), the pulmonary veins with stenotic lesions were aggressively unroofed and scar tissue was aggressively debrided extending to first-order, and occasionally second-order, branches within the lung parenchyma. Atretic veins were also unroofed if preoperative evaluation showed an open distal vessel. The pulmomary vein branches were then tacked back to the level of the pericardium using simple absorbable polydioxanone suture. Reconstruction of the left atrial well was done using sutureless technique by suturing the pericardium to left atrium using polypropylene suture material. The interatrial septum was usually closed with a 3-4 $\mathrm{mm}$ fenestrated piece of autologous pericardium.

\section{Postoperative Care}

Routine postoperative cardiac surgical care was provided. In eligible patients, adjunctive chemotherapy with bevacizumab and imatinib mesylate was given as directed by a research protocol (ClinicalTrials.gov NCT00891527). Inclusion in the chemotherapy protocol was at the discretion of the treating team. Follow-up imaging was obtained at the discretion of the attending cardiologist. By echocardiogram, if there was suspicion of recurrent stenoses of a repaired vein or development of stenosis in an unrepaired vein, and/or if there was associated RV hypertension or dysfunction, then a cardiac catheterization procedure was ordered. A priori, the goal was to treat new and recurrent stenoses with catheter-based interventions as much as possible. The decision to intervene was made by the individual interventionalist, largely based on the angiographic appearance of the vessel, and taking into account the overall clinical status of the patient, hemodynamic parameters, and the extent of disease involvement of other lung lobes. Our bias was to intervene on any affected lobar vessel with the appearance of $>50 \%$ narrowing in 1 view.

All catheterizations were done with general anesthesia and patients often would recover in the intensive care unit. Transseptal puncture was performed, if necessary, to access the pulmonary veins if pulmonary arterial angiography suggested obstruction. Interventions included balloon angioplasty and stenting. Stent placement was reserved as secondary therapy (ie, after balloon dilation failure) except in cases of perceived kinking or obstructive tortuosity of the venoatrial junction. We generally avoided stent placement in peripheral branches or in lobar branches where there was concern for jailing tributary vessels. In some cases, cutting balloons were used, not specifically to treat refractory lesions, but to create a distal aneurysm to allow stable balloon positioning in diffusely small and noncompliant vessels.

Lung transplantation was considered in patients with progressive disease not amenable to further surgical or catheter interventions.

\section{Statistical Analysis}

Categorical variables are summarized as number (percent), and continuous variables as median (range). Characteristics were compared for patients with primary versus nonprimary disease using the Fisher exact test for categorical variables and the Wilcoxon rank sum test for continuous variables. Similar comparisons were made for patients with at most 1 pulmonary vein intervention versus those with 2 or more pulmonary vein interventions. Times from surgery to death and from surgery to first catheterization with pulmonary vein intervention were compared using the log-rank test. Rates of catheterizations with pulmonary vein intervention were estimated as the total number of catheterizations with pulmonary vein intervention divided by the total patient-years of follow-up.

\section{RESULTS}

Between January 2007 and August 2013, we identified 49 patients with multivessel PVS who who underwent operation at our institution. Eighteen patients $(37 \%)$ had primary disease (without associated congenital heart disease) and 31 patients $(63 \%)$ had nonprimary or secondary disease (with associated congenital heart disease). Table 1 gives the clinical characteristics of the entire cohort and by diagnostic group. The primary group was more likely to be premature (born at $<37$ weeks gestational age) and tended to have more genetic anomalies. In the group with associated congenital heart disease $(\mathrm{n}=31), 5$ patients $(16 \%)$ had heterotaxy and $7(23 \%)$ had single ventricle physiology. Twenty-four patients $(49 \%)$ had a history of previous cardiac operations and 13 patients $(42 \%)$ had a diagnosis of total anomalous pulmonary venous return. Nineteen patients $(39 \%)$ had prior interventions on their pulmonary veins at other institutions.

The median CPB for the operation was 126 minutes (range, 61-257 minutes). The median crossclamp and CA times were 87 minutes (range, 24-229 minutes) and 50 minutes (range, 0-97 minutes), respectively.

Overall, 14 patients died during the follow-up period; mortality 1 year after surgery was estimated as $33 \%$ (95\% confidence interval, 20\%-52\%). There were 6 deaths in the primary group and 8 deaths in the nonprimary group; at 1 year after surgery, mortality was $43 \%$ in the primary group and $27 \%$ in the nonprimary group $(P=.40)$. Figure 1 shows the survival for the entire cohort and by 
TABLE 1. Characteristics of patients undergoing operation for pulmonary vein stenosis

\begin{tabular}{|c|c|c|c|c|}
\hline Characteristic & $\begin{array}{c}\text { Total } \\
(N=49)\end{array}$ & $\begin{array}{l}\text { Primary } \\
(n=18)\end{array}$ & $\begin{array}{c}\text { Nonprimary } \\
(\mathbf{n}=\mathbf{3 1})\end{array}$ & $\begin{array}{c}P \\
\text { value }\end{array}$ \\
\hline Male & $25(51)$ & $8(44)$ & $17(55)$ & .56 \\
\hline Female & $24(49)$ & $10(56)$ & $14(45)$ & \\
\hline Age at operation (mo) & $6(1-48)$ & $6(1-29)$ & $6(2-48)$ & .69 \\
\hline Weight at operation $(\mathrm{kg})$ & $4.9(2.1-13.4)$ & $4.9(2.7-9.2)$ & $5.1(2.1-13.4)$ & .94 \\
\hline Genetic Anomaly & & & & .07 \\
\hline Yes & $11(22)$ & $7(39)$ & $4(13)$ & \\
\hline No & $38(78)$ & $11(61)$ & $27(87)$ & \\
\hline Prematurity & & & & .002 \\
\hline Yes & $18(37)$ & $12(67)$ & $6(19)$ & \\
\hline No & $31(63)$ & $6(33)$ & $25(81)$ & \\
\hline Bilateral disease & & & & .27 \\
\hline Yes & $31(63)$ & $14(78)$ & $17(55)$ & \\
\hline No & $16(33)$ & $4(22)$ & $12(39)$ & \\
\hline Unclear & $2(4)$ & $0(0)$ & $2(6)$ & \\
\hline No. of veins involved & & & & .36 \\
\hline 2 & $15(31)$ & $5(28)$ & $10(32)$ & \\
\hline 3 & $13(27)$ & 7 (39) & $6(19)$ & \\
\hline 4 & $21(43)$ & $6(33)$ & $15(48)$ & \\
\hline Vein atresia & & & & .12 \\
\hline Yes & $15(31)$ & $8(44)$ & $7(23)$ & \\
\hline No & $34(69)$ & $10(56)$ & $24(77)$ & \\
\hline ASD & & & & 1.0 \\
\hline Yes & $47(96)$ & $17(94)$ & $30(97)$ & \\
\hline No & $2(4)$ & $1(6)$ & $1(3)$ & \\
\hline $\begin{array}{l}\text { Preoperative RVSP } \\
\quad>75 \% \text { systemic }\end{array}$ & & & & 1.0 \\
\hline Yes & $28(78)$ & $12(75)$ & $16(80)$ & \\
\hline No & $8(22)$ & $4(25)$ & $4(20)$ & \\
\hline Postoperative ECMO & & & & .13 \\
\hline Yes & $4(8)$ & $3(17)$ & $1(3)$ & \\
\hline No & $45(92)$ & $15(83)$ & $30(97)$ & \\
\hline $\begin{array}{l}\text { Postoperative } \\
\text { chemotherapy }\end{array}$ & & & & .55 \\
\hline Yes & $29(59)$ & $12(67)$ & $17(55)$ & \\
\hline No & $20(41)$ & $6(33)$ & $14(45)$ & \\
\hline
\end{tabular}

Values are presented as $\mathrm{n}(\%)$ or median (range). ASD, Atrial septal defect; RSVP, right ventricle systolic pressure; $E C M O$, extracorporeal membrane oxygenation.

diagnostic group. Younger age ( $<6$ months), lower weight $(<3 \mathrm{~kg})$, and lower RVSP $(<75 \%$ systemic $)$ were associated with mortality (Table 2).

Four patients with primary disease had RVSP $<75 \%$ systemic. These patients underwent operation due to the severity of their anatomic disease. Five patients died who had RVSP $<75 \%$ systemic. One patient died on postoperative day 12 after developing lung injury from a long bypass run and bleeding. He required extracorporeal membrane oxygenation and was unable to be weaned from support. Another patient died as a result of respiratory failure from a possible viral illness in the context of systemic pulmonary hypertension with stable vein disease. Two other patients died with respiratory failure in the context of progressive vein disease. Another patient died of unknown cause.

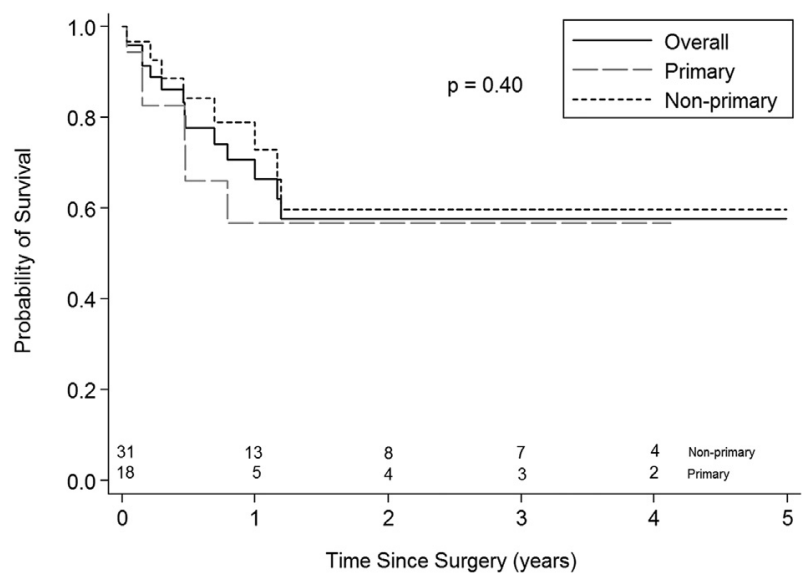

FIGURE 1. Kaplan-Meier survival curve of patients operated for multivessel pulmonary vein stenosis. In the primary group (ie, those without associated congenital heart disease), estimated survival is $57 \%$ at both 1 and 2 years postsurgery (95\% confidence interval [CI], $26 \%-78 \%$ ). In the nonprimary group (ie, those with associated congenital heart disease), estimated survival is $73 \%(95 \% \mathrm{CI}, 48 \%-87 \%)$ at 1 year and $60 \%(95 \% \mathrm{CI}, 34 \%-78 \%)$ at 2 years.

Thirty-nine patients $(80 \%)$ had at least 1 postoperative catheterization. The median number of catheterizations per patient was 2 (range, 0-14). The median time from operation to catheterization was 1.7 months (range, 3 days-38.5 months). Twenty-nine patients (59\%) had at least 1 catheterization with intervention on the pulmonary veins. The median number of catheterizations with intervention per patient was 1 (range, $0-14$ ). Six patients $(12 \%)$ had only 1 catheterization with intervention; 12 patients (24\%) had 2 to 4 catheterizations; and 11 patients $(22 \%)$ had $\geq 5$ catheterizations. The median time from operation to first catheter intervention was 1.9 months (range, 3 days-11.8 months). Only 1 patient had a reoperation for recurrent PVS.

The cumulative incidence to the first catheterization with intervention for the overall group was approximately $75 \%$ at 1 year. For the 29 patients who had 1 catheter intervention, the cumulative incidence of a second catheterization with intervention was about $90 \%$ within the subsequent year.

There were no associations with need for catheterization with pulmonary vein intervention (Table 3 ) or the number of catheterizations with pulmonary vein intervention. Although there is a need for ongoing interventions in many patients, the rate of catheterizations with pulmonary vein interventions appeared to significantly decrease over time, when accounting for number of catheterizations with pulmonary vein interventions and available follow-up (Table 4).

Ten patients were listed for lung transplantation: 3 patients were transplanted with 1 posttransplant death, 3 patients died waiting, and 4 patients were de-listed. Patients 
TABLE 2. Associations with mortality after operation for multivessel pulmonary vein stenosis

\begin{tabular}{|c|c|c|c|}
\hline Characteristic & $\begin{array}{c}\text { Mortality } \\
\text { yes }(n=14)\end{array}$ & $\begin{array}{c}\text { Mortality } \\
\text { no }(\mathbf{n}=\mathbf{3 5})\end{array}$ & $\begin{array}{c}\text { Log-rank } \\
P \text { value }\end{array}$ \\
\hline Primary & $6(43)$ & $12(34)$ & .40 \\
\hline Nonprimary & $8(57)$ & $23(66)$ & \\
\hline Male & $6(43)$ & $19(54)$ & .53 \\
\hline Female & $8(57)$ & $16(46)$ & \\
\hline Age at operation (mo) & $5(2-18)$ & $7(1-48)$ & $.03 *$ \\
\hline Age at operation $<6 \mathrm{mo}$ & & & .004 \\
\hline Yes & $11(79)$ & $11(31)$ & \\
\hline No & $3(21)$ & $24(69)$ & \\
\hline Weight at operation $(\mathrm{kg})$ & $4.0(2.1-8.8)$ & $5.2(3.0-13.4)$ & $.02 *$ \\
\hline Weight at operation $<3 \mathrm{~kg}$ & & & $<.001$ \\
\hline Yes & $2(14)$ & $0(0)$ & \\
\hline No & $12(86)$ & $35(100)$ & \\
\hline Genetic anomaly & & & .59 \\
\hline Yes & $4(29)$ & $7(20)$ & \\
\hline No & $10(71)$ & $28(80)$ & \\
\hline Prematurity & & & .84 \\
\hline Yes & $6(43)$ & $12(34)$ & \\
\hline No & $8(57)$ & $23(66)$ & \\
\hline Bilateral disease & & & .63 \\
\hline Yes & $10(71)$ & $21(60)$ & \\
\hline No & $4(29)$ & $12(34)$ & \\
\hline Unclear & $0(0)$ & $2(6)$ & \\
\hline No. of veins involved & & & .85 \\
\hline 2 & $3(21)$ & $12(34)$ & \\
\hline 3 & $4(29)$ & $9(26)$ & \\
\hline 4 & $7(50)$ & $9(26)$ & \\
\hline Vein atresia & & & .43 \\
\hline Yes & $4(29)$ & $11(31)$ & \\
\hline No & $10(71)$ & $24(69)$ & \\
\hline $\begin{array}{l}\text { Preoperative RVSP } \\
>75 \% \text { systemic }\end{array}$ & & & .04 \\
\hline Yes & $5(50)$ & $23(88)$ & \\
\hline No & $5(50)$ & $3(12)$ & \\
\hline Single ventricle & & & .94 \\
\hline Yes & $2(14)$ & $5(14)$ & \\
\hline No & $12(86)$ & $30(86)$ & \\
\hline Heterotaxy & & & .82 \\
\hline Yes & $1(7)$ & $4(11)$ & \\
\hline No & $13(93)$ & $31(89)$ & \\
\hline ASD & & & .60 \\
\hline Yes & $13(93)$ & $34(97)$ & \\
\hline No & $1(7)$ & $1(3)$ & \\
\hline Prior operation & & & .16 \\
\hline Yes & $5(36)$ & $19(54)$ & \\
\hline No & $9(64)$ & $16(46)$ & \\
\hline TAPVR & & & .37 \\
\hline Yes & $3(21)$ & $10(29)$ & \\
\hline No & $11(79)$ & $25(71)$ & \\
\hline Postoperative ECMO & & & $.57 \dagger$ \\
\hline Yes & $2(14)$ & $2(6)$ & \\
\hline No & $12(86)$ & $33(94)$ & \\
\hline
\end{tabular}

TABLE 2. Continued

\begin{tabular}{|c|c|c|c|}
\hline Characteristic & $\begin{array}{c}\text { Mortality } \\
\text { yes }(n=14)\end{array}$ & $\begin{array}{c}\text { Mortality } \\
\text { no }(\mathbf{n}=\mathbf{3 5})\end{array}$ & $\begin{array}{c}\text { Log-rank } \\
P \text { value }\end{array}$ \\
\hline Postoperative chemotherapy & & & $1.0^{\dagger}$ \\
\hline Yes & $8(57)$ & $21(60)$ & \\
\hline No & $6(43)$ & $14(40)$ & \\
\hline
\end{tabular}

were de-listed because catheter interventions decreased the burden of their disease and they were clinically stabilized and improved. The composite end point of death and lung transplantation, or transplant-free survival, is shown in Figure 2.

\section{DISCUSSION}

In a recent cohort of young children with multivessel PVS undergoing operation at our institution, we found acceptable early survival. Younger age and lower weight at time of operation, and lower preoperative RVSP were associated with mortality. Most of the patients needed catheter-based interventions during the follow-up period, but we could not identify any associated factors for these interventions. The rate of interventions may decrease over time. Some patients were able to come off the lung transplant waiting list.

The prognosis for patients with PVS is considered dismal without treatment. Surgical interventions have had limited success. ${ }^{9-15}$ We found acceptable early survival in our recent cohort. Referral bias may have influenced our results, because only patients who survived to be referred are included. On the other hand, the referred patients may have had more severe disease. Our aggressive approach to the operation to relieve pulmonary venous obstructions may have contributed to the observed survival. We also have a low threshold to image and perform dilation or stenting for recurrent stenoses. Many of our patients were closely followed as part of an antiproliferative chemotherapy protocol for PVS.

We observed that younger age and lower weight at time of operation were associated with mortality, in particular, age younger than 6 months and weight $<3 \mathrm{~kg}$. These patients may have had more aggressive disease at time of presentation. Furthermore, smaller and younger patients pose technical challenges for surgeons and interventionalists. It is uncertain whether patients can or should be bridged to operation at an older age or heavier weight to improve outcomes. It has been our experience that these patients will not grow due to their illness severity. We 
TABLE 3. Associations with catheter-based pulmonary vein interventions after operation for multivessel pulmonary vein stenosis

\begin{tabular}{|c|c|c|c|}
\hline Characteristic & $\begin{array}{c}\text { Pulmonary vein } \\
\text { intervention } \\
\text { yes }(\mathbf{n}=\mathbf{2 9}) \\
\end{array}$ & $\begin{array}{c}\text { Pulmonary vein } \\
\text { intervention } \\
\text { no }(\mathbf{n}=\mathbf{2 0}) \\
\end{array}$ & $\begin{array}{c}\text { Log-rank } \\
P \text { value } \\
\end{array}$ \\
\hline Primary & $12(41)$ & $6(30)$ & .13 \\
\hline Nonprimary & $17(59)$ & $14(70)$ & \\
\hline Male & $12(41)$ & $13(65)$ & .10 \\
\hline Female & $17(59)$ & $7(35)$ & \\
\hline Age at operation (mo) & $6(1-48)$ & $6(1-17)$ & $.70^{*}$ \\
\hline Age at operation $<6 \mathrm{mo}$ & & & .73 \\
\hline Yes & $13(45)$ & $9(45)$ & \\
\hline No & $16(55)$ & $11(55)$ & \\
\hline Weight at operation $(\mathrm{kg})$ & $5.0(2.1-13.4)$ & $4.8(3.0-8.9)$ & $.99 *$ \\
\hline Weight at operation $<3 \mathrm{~kg}$ & & & .36 \\
\hline Yes & $2(7)$ & $0(0)$ & \\
\hline No & $27(93)$ & $20(100)$ & \\
\hline Genetic anomaly & & & .79 \\
\hline Yes & $7(24)$ & $4(20)$ & \\
\hline No & $22(76)$ & $16(80)$ & \\
\hline Prematurity & & & .26 \\
\hline Yes & $12(41)$ & $6(30)$ & \\
\hline No & $17(59)$ & $14(70)$ & \\
\hline Bilateral disease & & & .42 \\
\hline Yes & $19(66)$ & $12(60)$ & \\
\hline No & $9(31)$ & $7(35)$ & \\
\hline Unclear & $1(3)$ & $1(5)$ & \\
\hline No. of veins involved & & & .99 \\
\hline 2 & $9(31)$ & $6(30)$ & \\
\hline 3 & $8(28)$ & $5(25)$ & \\
\hline 4 & $12(41)$ & $9(45)$ & \\
\hline Vein atresia & & & .54 \\
\hline Yes & $9(31)$ & $6(30)$ & \\
\hline No & $20(69)$ & $14(70)$ & \\
\hline $\begin{array}{l}\text { Preoperative RVSP } \\
>75 \% \text { systemic }\end{array}$ & & & .51 \\
\hline Yes & $18(82)$ & $10(71)$ & \\
\hline No & $4(18)$ & $4(29)$ & \\
\hline Single ventricle & & & .70 \\
\hline Yes & $4(14)$ & $3(15)$ & \\
\hline No & $25(86)$ & $17(85)$ & \\
\hline Heterotaxy & & & .64 \\
\hline Yes & $3(10)$ & $2(10)$ & \\
\hline No & $26(90)$ & $18(90)$ & \\
\hline ASD & & & .10 \\
\hline Yes & $27(93)$ & $20(100)$ & \\
\hline No & $2(7)$ & $0(0)$ & \\
\hline Prior operation & & & .50 \\
\hline Yes & $14(48)$ & $10(50)$ & \\
\hline No & $15(52)$ & $10(50)$ & \\
\hline TAPVR & & & .50 \\
\hline Yes & $8(28)$ & $5(25)$ & \\
\hline No & $21(72)$ & $15(75)$ & \\
\hline Postoperative ECMO & & & $.29 \dagger$ \\
\hline Yes & $1(3)$ & $3(15)$ & \\
\hline No & $28(97)$ & $17(85)$ & \\
\hline
\end{tabular}

TABLE 3. Continued

\begin{tabular}{|c|c|c|c|}
\hline Characteristic & $\begin{array}{c}\text { Pulmonary vein } \\
\text { intervention } \\
\text { yes }(\mathbf{n}=29) \\
\end{array}$ & $\begin{array}{c}\text { Pulmonary vein } \\
\text { intervention } \\
\text { no }(\mathbf{n}=\mathbf{2 0}) \\
\end{array}$ & $\begin{array}{c}\text { Log-rank } \\
P \text { value } \\
\end{array}$ \\
\hline $\begin{array}{l}\text { Postoperative } \\
\text { chemotherapy }\end{array}$ & & & $.38 \dagger$ \\
\hline Yes & $19(66)$ & $10(50)$ & \\
\hline No & $10(31)$ & $10(50)$ & \\
\hline
\end{tabular}

tend to see patients referred to us who are very ill, have undergone various therapies, and are failing. It is our current practice to intervene early. A preoperative cardiac catheterization procedure is performed to dilate stenoses in an attempt to relieve pulmonary hypertension, followed by early operation.

We also observed that a lower RVSP was associated with mortality. Patients with lower RV pressures could be those with impaired RV function. Patients with higher RVSP could have been those who obtained the greatest benefit from relief of PVS and therefore had better survival. The number of patients with RVSP less than three-fourths systemic were few and this result is difficult to interpret. We were unable to identify any common features in this small group, particularly with respect to RV function.

Bilateral pulmonary venous disease was not associated with mortality in our series. Bilateral disease has been found to be associated with worse prognosis in inception cohorts of PVS. ${ }^{4}$ Our cohort included patients who were already treated surgically for pulmonary vein disease and were referred with advanced disease. Bilaterality was not defined at the time of original presentation, but further along in the modified natural history of the condition and just before operation at our institution. Our surgical technique involves aggressive resection of stenotic and atretic lesions of the pulmonary veins. Pulmonary vein atresia was not a contraindication to attempt at surgical relief. ${ }^{18}$ It is not uncommon to resect tissue out to first-order, and sometimes second-order, pulmonary vein branches. We believe that this is an important aspect of the operation to completely resect all macroscopically involved tissue. Because of the nature of the resection, the remaining open veins are within the parenchyma of the lung and it is necessary to perform a sutureless repair to the atrium. The operation can be quite extensive, as evidenced by long $\mathrm{CPB}$, crossclamp, and $\mathrm{CA}$ times. The physiologic stress on the patient has to be weighed against a technically satisfactory result.

Most of our patients had catheterizations and interventions on the pulmonary veins for recurrent PVS. 
TABLE 4. Rate of catheterization with pulmonary vein intervention

\begin{tabular}{lcccc}
\hline Year postsurgery & $\begin{array}{c}\text { Total no. of catheterizations } \\
\text { with PV interventions }\end{array}$ & $\begin{array}{c}\text { Total follow-up } \\
\text { time (mo) }\end{array}$ & $\begin{array}{c}\text { Catheterization with PV } \\
\text { intervention rate per patient month }\end{array}$ & $\begin{array}{c}\text { Catheterization with PV } \\
\text { intervention rate per patient year }\end{array}$ \\
\hline 1 & 95 & 338.7 & 0.28 & 3.4 \\
2 & 16 & 136.2 & 0.12 & 1.4 \\
3 & 7 & 88.5 & 0.08 & 0.9 \\
\hline
\end{tabular}

$P V$, Pulmonary vein.

If interventions are necessary, they are needed early after operation. The likelihood of ongoing interventions is high. We believe that close follow-up and aggressive treatment of recurrent stenoses is important and may contribute to improved survival. There may be accrued risk of repeated catheterizations with interventions, such as catastrophic target vessel trauma and systemic embolic events, which we have observed.

Although we were unable to identify any associations with the need for catheter-based interventions, we recognized 3 clinical patterns. The first is a group of patients that have fewer than 1 or 2 interventions. The second is a group of patients who have ongoing multiple interventions, even beyond a year of follow-up. The third is a group of patients who have multiple interventions during the first year after operation who are very ill, with some going on to die. We have not been able to predict the clinical course of individual patients.

The rate of catheterization with pulmonary vein interventions did appear to decrease over time, when expressed in patient-years. We hypothesize that stabilization or burnout of the disease process may explain this observation. The influence of chemotherapy is not yet known. If our hypothesis is correct, we would argue for close surveillance and a low

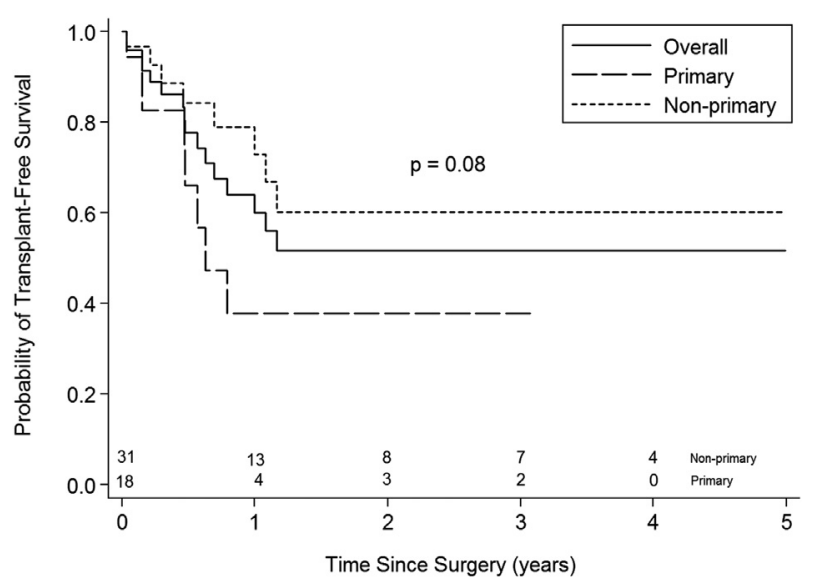

FIGURE 2. Transplant-free survival: Composite end point of death and lung transplantation. In the primary group (ie, those without associated congenital heart disease), estimated transplant-free survival is $38 \%$ at both 1 and 2 years postsurgery (95\% confidence interval [CI], $12 \%-64 \%$ ). In the nonprimary group (ie, those with associated congenital heart disease), estimated survival is $73 \%(95 \% \mathrm{CI}, 48 \%-87 \%)$ at 1 year and $60 \%(95 \% \mathrm{CI}, 34 \%-78 \%)$ at 2 years. threshold for catheter-based interventions for recurrent PVSs. To confirm this observation, we are analyzing those patients with primary PVS to detail the natural history of each pulmonary vein and describe the nature of recurrent stenoses and their effect on survival.

Lung transplantation remains an option for patients with terminal pulmonary vein disease. ${ }^{16}$ We have successfully transplanted patients with PVS after sutureless repair. Pretransplant considerations include phrenic nerve function, recurrent laryngeal nerve function, type of sutureless repair, and RV function. In patients who are receiving bevacizumab, an exchange transfusion is done at the time of transplant because of concerns for wound healing. In our cohort, some patients were able to come off the transplant list. We believe that performing catheter-based interventions for recurrent stenoses may delay or obviate the need for transplantation. We have not offered heart-lung transplantation for patients with RV failure.

Chemotherapeutic agents that target neointimal proliferation hold promise in the treatment of PVS. There is an ongoing prospective open-label Food and Drug Administration-approved study on the use of bevacizumab and imatinib for multivessel PVS. Details of the trial, including the inclusion and exclusion criteria, can be found at ClinicalTrials.gov (ID: NCT00891527). This trial includes patients who underwent and did not undergo operation. We did not observe that the use of chemotherapy was a predictor of survival in our cohort, although only $59 \%$ of our patients received chemotherapy.

\section{Study Limitations}

Our study is a restrospective review of cases from a single institution. Our patients were mostly referred, were at various stages of their disease, and included patients with primary and nonprimary disease. With the exception of those patients receiving chemotherapy, the postoperative follow-up and decisions regarding imaging and interventions were not based on a protocol. The inclusion of patients in an ongoing chemotherapy trial for PVS was at the discretion of the treating team. Some of the follow-up was done at the referring institutions. Our results only reflect early outcomes.

Defining a satisfactory outcome for this challenging group of patients is difficult. We specifically looked at mortality and need for catheterization and catheter 
interventions in our cohort. Survival has to be balanced against the morbidity and decreased quality of life related to multiple interventions and chemotherapeutic treatments. A patent pulmonary vein as a potential satisfactory outcome may be less relevant in the face of persistent pulmonary hypertension, potential need for lung transplantation, or death. Reduced pulmonary hypertension is another potential outcome, but may not be relevant if there is eventual mortality. Our traditional outcomes in this disease need to be put in context and further research into the neurodevelopment-related outcomes and quality of life of patients with PVS needs to be done.

\section{CONCLUSIONS}

In a recent cohort of young children with multivessel PVS undergoing operation at our institution, we observed acceptable early survival. Catheter-based interventions were common for recurrent stenoses, but their need may decrease over time. Lung transplantation remains a viable treatment option.

\section{Conflict of Interest Statement}

Authors have nothing to disclose with regard to commercial support.

\section{References}

1. Sadr IM, Tan PE, Kieran MW, Jenkins KJ. Mechanism of pulmonary vein stenosis in infants with normally connected veins. Am J Cardiol. 2000;86:577-9. A10.

2. Holt DB, Moller JH, Larson S, Johnson MC. Primary pulmonary vein stenosis. Am J Cardiol. 2007;99:568-72.

3. Seale AN, Webber SA, Uemura H, Partridge J, Roughton M, Ho SY, et al. Pulmonary vein stenosis: the UK, Ireland and Sweden collaborative study. Heart. 2009;95:1944-9.

4. Balasubramanian S, Rehman M, Gauvreau K, Jenkins KJ. Bilateral disease and early age at presentation are associated with shorter survival in patients with congenital heart disease and intraluminal pulmonary vein stenosis. Congenit Heart Dis. 2012;7:378-86

5. Drossner DM, Kim DW, Maher KO, Mahle WT. Pulmonary vein stenosis: prematurity and associated conditions. Pediatrics. 2008;122:e656-61.
6. Lock JE, Bass JL, Castaneda-Zuniga W, Fuhrman BP, Rashkind WJ, Lucas RV Jr. Dilation angioplasty of congenital or operative narrowings of venous channels. Circulation. 1984;70:457-64

7. Balasubramanian S, Marshall AC, Gauvreau K, Peng LF, Nugent AW, Lock JE, et al. Outcomes after stent implantation for the treatment of congenital and postoperative pulmonary vein stenosis in children. Circ Cardiovasc Interv. 2012;5: 109-17.

8. Hickey EJ, Caldarone CA. Surgical management of post-repair pulmonary vein stenosis. Semin Thorac Cardiovasc Surg Pediatr Card Surg Annu. 2011;14 101-8.

9. Bini RM, Cleveland DC, Ceballos R, Bargeron LM Jr, Pacifico AD, Kirklin JW Congenital pulmonary vein stenosis. Am J Cardiol. 1984;54:369-75.

10. van Son JA, Danielson GK, Puga FJ, Edwards WD, Driscoll DJ. Repair of congenital and acquired pulmonary vein stenosis. Ann Thorac Surg. 1995;60: 144-50.

11. Breinholt JP, Hawkins JA, Minich LA, Tani LY, Orsmond GS, Ritter S, et al. Pulmonary vein stenosis with normal connection: associated cardiac abnormalities and variable outcome. Ann Thorac Surg. 1999;68:164-8.

12. Ricci M, Elliott M, Cohen GA, Catalan G, Stark J, de Leval MR, et al Management of pulmonary venous obstruction after correction of TAPVC: risk factors for adverse outcome. Eur J Cardiothorac Surg. 2003;24:28-36; discussion 36.

13. Devaney EJ, Chang AC, Ohye RG, Bove EL. Management of congenital and acquired pulmonary vein stenosis. Ann Thorac Surg. 2006;81:992-5; discussion 995-6.

14. Viola N, Alghamdi AA, Perrin DG, Wilson GJ, Coles JG, Caldarone CA. Primary pulmonary vein stenosis: the impact of sutureless repair on survival. $J$ Thorac Cardiovasc Surg. 2011;142:344-50.

15. Song MK, Bae EJ, Jeong SI, Kang IS, Kim NK, Choi JY, et al. Clinical characteristics and prognostic factors of primary pulmonary vein stenosis or atresia in children. Ann Thorac Surg. 2013;95:229-34.

16. Bharat A, Epstein DJ, Grady M, Faro A, Michelson P, Sweet SC, et al. Lung transplant is a viable treatment option for patients with congenital and acquired pulmonary vein stenosis. J Heart Lung Transplant. 2013;32:621-5.

17. Rehman M, Jenkins KJ, Juraszek AL, Connor JA, Gauvreau K, Muneeb M, et al. A prospective phase II trial of vinblastine and methotrexate in multivessel intraluminal pulmonary vein stenosis in infants and children. Congenit Heart Dis. 2011;6:608-23.

18. Shuhaiber J, Rehman M, Jenkins K, Fynn-Thompson F, Bacha E. The role of surgical therapy for pulmonary vein atresia in childhood. Pediatr Cardiol. 2011;32:639-45.

Key Words: congenital heart disease, pulmonary vein, pulmonary vein stenosis, pulmonary vein operation, pulmonary vein dilation, lung transplanation, pulmonary hypertension 